\title{
O silêncio de Frei Caneca em $O$ Auto do Frade de João Cabral de Melo Neto
}

\author{
Susana Vernieri*
}

\begin{abstract}
Resumo: O texto trata da análise de um poema escrito por João Cabral de Melo Neto em 1984, data em que o Brasil vive o fim da ditadura militar. O Auto do Frade conta a história da execução do líder revolucionário Frei Caneca que foi morto nas ruas de Recife em 1825. O tema do silêncio é enfatizado no trabalho.
\end{abstract}

Palavras-chave: Poesia; João Cabral de Melo Neto; Auto do Frade; Literatura brasileira.

\begin{abstract}
This text deals with the analysis of a poem written by João Cabral de Melo Neto in 1984, when Brazil was going through the end of the military dictatorship. O Auto do Frade tells the history of the execution of the revolutionary leader Frei Caneca, killed on the streets of Recife in 1825. The theme of silence is emphasized in this study.
\end{abstract}

Keywords: Poetry; João Cabral de Melo Neto; Auto do Frade; Brazilian literature.

Frei Caneca, ou Joaquim do Amor Divino Rebelo ${ }^{1}$, é o personagem principal do Auto do Frade, peça de João Cabral, de 1984. A obra conta a história do herói da Revolução Constitucionalista de Pernambuco, de 1824, que é levado à execução e à morte. Para João

\footnotetext{
* Susana Vernieri é formada em Direito pela PUCRS e em jornalismo pela UFRGS. Tem mestrado e doutorado em Literatura Brasileira na UFRGS, com a dissertação e a tese sobre a poesia de João Cabral de Melo Neto. Publicou $O$ Capibaribe de João Cabral em Um Cão sem Plumas e O Rio: Duas Águas? (Editora Annablumme, 1998) e a novela Caminho de Telêmaco (Editora Criação Humana, 2002). Com o primeiro livro, recebeu menção honrosa do Prêmio Jordão Emerenciano (1998) na categoria Ensaio, patrocinado pela cidade do Recife. Atualmente, faz pós-doutorado em Teoria da Literatura na PUCRS sob a orientação da Prof ${ }^{a}$. Regina Zilberman.

${ }^{1}$ Frei Joaquim do Amor Divino Caneca nasceu em Recife, em 1779, filho de Domingos da Silva Rabelo e Francisca Maria Alexandrina de Siqueira. O apelido Caneca foi devido à profissão de seu pai, dono de uma oficina de tanoeiro. Ordenou-se em 1799, aos vinte anos, e dedicou-se ao ensino. Em 1817, envolveu-se numa rebelião contra o governo imperial que durou menos de três meses. Derrotado, foi acusado de aprender o ofício de soldado, de ser muito dedicado ao serviço, de ser declamador, de fugir de Utinga para o Recife, de ser capitão de guerrilhas, de ir ao exército do sul para missionar, de fugir com os rebeldes e, na debandada, de ser preso. Preso, é levado na corveta Mercúrio para Bahia e lá fica na cadeia da Relação até 1821. Sua prisão é feita da seguinte forma: antes de embarcar ataram-lhe ao pescoço uma grossa corrente de ferro. Com a cabeça descoberta, ele e mais três, e estes três amarrados os braços com cordas, precediam a marcha dos demais que, em filas, caminhavam, rodeados de forte destacamento de tropa, na populosa cidade do Recife. Grilhões aos pés substituem os laços de corda nos braços dos três que o traziam; uma gargalheira atando estreitamente os pescoços de todos os presos, com as duas pontas cravadas no pavimento, obrigava-os a permanecerem deitados, sem outro leito fora das alcatroadas tábuas do mesmo porão. Foram esses homens rebeldes que transformaram os cárceres da Relação numa escola de altos estudos, na promiscuidade dos escravos que ali iam receber castigos de açoites, às vezes 500, à noite, alumiados por magro candeeiro de óleo de baleia, acorrentados. Ali Frei Caneca escreveu a sua Gramática Portuguesa, lecionou e fez versos. In: SODRÉ, 1983, p. 90-132.
} 
Alexandre Barbosa (BARBOSA, 2001, p. 83), circula no texto não só a imagem histórica, traduzindo gestos heróicos, mas, sobretudo, a tensão entre o que é representação da história e a técnica narrativa do auto, enquanto forma dramática privilegiada pelo poeta que ocupa o verso cabralino. "Um verso que, sem esquecer as lições anteriores, permite a passagem do social para o mais largamente histórico, sem perda das exigências de uma composição pessoal arduamente aprendida." (BARBOSA, 2001, p. 83).

Antes de fazermos uma análise mais aprofundada do texto poético cabralino, valeria retomar um pouco a história de Frei Caneca nos momentos que antecedem sua execução. Monge carmelita, ele viveu num Pernambuco que conhecia a imprensa desde 1817, data recorde se for feita uma comparação com as outras províncias brasileiras ${ }^{2}$. Ou seja, cedo as idéias já circulavam pelo lugar e clamavam pelo fim do Império.

Com o pensamento nacional já plenamente permeado por idéias de independência, no dia 25 de dezembro de 1825, Frei Caneca lança o primeiro número do seu Tifis Pernambucano:

Anunciava, desde logo, que a pátria parecia uma 'nau destroçada pela fúria oceânica, ameaçando soçobro, carecendo de ajuda decidida e abnegada de todos os seus filhos'. Concitava os pernambucanos a permanecerem alertas. Informava a dissolução da Constituinte, tomando posição: 'Para desgraça deste Império, realizaram-se os temores dos que sabiam pesar o perigo da força armada nas mãos de um príncipe jovem, rodeado de lisonjeiros sem caráter, inimigos encarniçados do Brasil”. (SODRÉ, 1983, p. 89)

Frei Caneca também pregava a união para a defesa da independência e da liberdade. Combatia a cúpula da Igreja, no caso do cabido de Olinda, cujos membros, dizia, 'estimulam a servidão e o despotismo'. Para Werneck, Caneca era bem o homem da rebeldia da revolução pernambucana de 1817. "Um daqueles que tinha transformado, segundo o conde dos Arcos, Pernambuco num covil de monstros infiéis, indivíduos infames, ridículos, desprezíveis e bandidos." (SODRÉ, 1983, p. 90). O pesquisador segue dizendo que não era de se espantar que servidores portugueses assim proclamassem a respeito do monge carmelita. Espanta que a historiografia oficial tenha continuado a qualificá-lo assim. Indivíduo que se portava, entretanto, com austeridade indestrutível. Werneck retoma a crônica da época para lembrar que, quando as tropas realistas tomaram Pernambuco após a revolução, encontraram, intacto,

\footnotetext{
${ }^{2}$ Para termos uma idéia da história da imprensa nacional em seus primórdios, vale lembrar algumas datas e periódicos: o Correio Brasiliense, considerado o primeiro jornal brasileiro, pois, apesar de impresso na Inglaterra, era feito por brasileiros e livre da censura portuguesa, começou a ser publicado em 1808. Em 1811, surgiu, na Bahia, o A Idade do Ouro no Brasil. No ano seguinte circulam, a partir do Rio de Janeiro, dois números de Variedades ou Ensaios de Literatura e, em 1813, é a vez de O Patriota. Ambos são jornais de forte característica literária. No ano de 1814 é a vez do início da circulação de jornais de cunho comercial. Entre 1808 e 1818 há também periódicos que circularam em Londres, entrando no Brasil, estipendiados ou não pela coroa portuguesa. São jornais que defendiam o Império. In: SODRE, 1983, p. 23-34.
} 
num cofre, no engenho onde acampavam os revoltosos, tudo quanto as autoridades haviam deixado no dia da capitulação.

Damos agora um salto no tempo e ancoramos no período em que João Cabral escreve o Auto do Frade. É 1981, em Quito, mesmo ano em que o diplomata-poeta deixa o Equador ao ser nomeado embaixador em Honduras. Será naquele país, em Tegucigalpa, que Cabral terminará sua peça, em 1983. Distante do Brasil nascia o Auto.

No ano de sua concepção é, pela primeira vez, identificado o vírus da Aids no mundo. No ano de sua publicação, Raul Alfonsín é eleito, por voto livre, presidente da Argentina depois do fim da Guerra das Malvinas e depois de anos de ditadura que cobriu o país de dor. Infelizmente, entre 1981 e 1983, o Brasil ainda está sob ditadura militar.

Tancredo Neves, primeiro presidente civil depois de quase duas décadas de fardas no poder, ainda estava longe de ser eleito. Só o será por um colégio eleitoral, em 1986 (ARNS, 1985, p. 11-27). E mal toma posse, morre em função de complicações após uma cirurgia no intestino. Mas a faixa temporal em que se enquadra a composição do Frei Caneca cabralino não é de todo negra. Há ventos de esperança no horizonte do país. O exemplo da vizinha Argentina é uma das brisas. Parece ser possível sonhar uma pátria mais livre; e a política começa a ser debatida nas ruas.

João Cabral nomeia seu auto de um poema para vozes e o dedica a seus filhos com uma epígrafe de Gertrude Stein. Nela, a poeta americana saúda alguém e assume um tom nem de prazer, nem de desprazer. O verso ("I salute you and I say I am not displeased I am not pleased, I am not pleased I am not displeased”) de Stein é como uma apologia da frieza, mas é preferível crer que João Cabral escolheu-o por um implícito sentido zen que ele contém. $\mathrm{O}$ mesmo sentimento que se verá assumido por Caneca ao longo de sua via crucis rumo à execução.

A trajetória do monge inicia-se na cela onde dorme e é observado pelos dois algozes: o carcereiro e o provincial. Ambos conversam sobre o sono pesado do preso que parece não se importar com seu destino e sobre as diferenças do sono da morte e do sono da vida.

\footnotetext{
- Dorme.

- Dorme como se não fosse com ele.

- Dorme como uma criança dorme.

- Dorme como em pouco, morto, vai dormir.

- Ignora todo esse circo lá embaixo.

- Não é circo. É a lei que monta o espetáculo.

- Dorme. No mais fundo do poço onde se dorme.

— Já terá tempo de dormir: a morte inteira.

- Não se dorme na morte. Não é sono.

— Não é sono. E não terá, como agora, quem o acorde.

- Que durma ainda. Não tem hora marcada.

- Mas é preciso acordá-lo. Já há gente para o espetáculo.
} 
- [...] Melhor arrombar a porta. Sacudi-lo.

— Dorme fundo como um morto.

- Mas está vivo. Vamos ressuscitá-lo.

— Deste sono ainda pode ser ressuscitado.

- Deste sono, sim. Do outro nem que ponham a porta abaixo.

— Está dormindo como um santo.

- Santo não dorme. Os santos são é moucos. Mas têm olhos bem abertos. Vi na igreja. (MELO NETO, 1994, p. 465)

Caneca tem uma das qualidades dos santos ao dormir: é mouco, pois não acorda com os barulhos. Talvez também enxergue de forma privilegiada, apesar de ter os olhos cerrados. Certo é que o Frei é um ser humano a caminho da forca e no corredor da morte que, paradoxalmente, acorda ávido de vida.

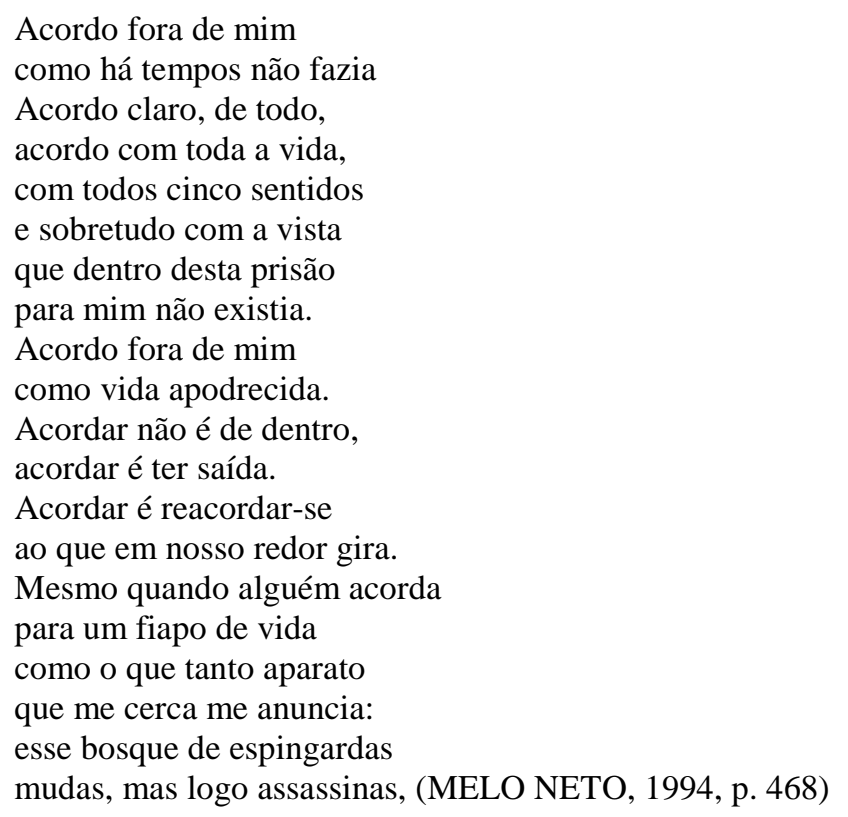

É a iminência da morte com seus objetos característicos que aguçam a vontade de viver os fiapos de minuto que restam ao condenado. A justiça não estará presente na execução, o juiz partiu em visita a seu imenso canavial. O condenado chega às ruas e, na voz da gente nas calçadas, vem "lavado e leve,/como ia ao Convento do Carmo./_ Quando ia ditar sua geometria./— Ou fosse a redação do diário [...] Ei-lo que vem descendo a escada,/degrau a degrau. Como vem calmo./- Crê no mundo, e quis consertá-lo./- E ainda crê, já condenado?/Sabe que não o consertará./— Mas que virão para imitá-lo", (MELO NETO, 1994, p. 470).

A gente nas calçadas indigna-se com o tratamento dado a Caneca. Seja com a corda amarrada em seu pescoço, lembrando um bicho maneteado, ou comparando o cortejo a caminho da forca com o de uma procissão onde o santo é o monge. Há também uma pergunta que o povo faz: por que o silêncio de Caneca?

\footnotetext{
- Por que será que ele não fala,
} nem diz nada sua boca muda? 
- Senhor que ele foi das palavras não há uma só que hoje acuda.

- Contaram-me que na cadeia lhe haviam arrancado a língua.

- Pois se ele pudesse falar tropa ou juiz, quem o detinha?

- Cortaram-lhe a língua na cela para que não confessasse.

- Condenado que foi à forca, que ao inferno se condenasse. — Não fala porque lhe proibiram na cela onde as caveiras limpas Os muros que o tinham na cela são agora essas togas, batinas. - Lá não tinha com quem falar, as paredes nem eco tinham. (MELO NETO, 1994, p. 474-475)

Uns dizem que o revolucionário não fala porque arrancaram sua língua na cadeia, arrancaram-na para que não pudesse confessar e assim fosse condenado ao inferno. Outros falam que foi proibido de falar na cela, pois ninguém o escutaria. Os muros sem ouvidos da prisão são como as pretas togas jurídicas e as batinas cléricas. Não há porque falar para surdos.

De repente, o Frei fala. Protesta contra o tom de romaria, procissão que está sendo dado a seu caminho em direção à forca. No máximo aceita que "Talvez seja só um enterro/em que o morto caminharia,/que não vai entre seis tábuas/mas entre seis carabinas," (MELO NETO, 1994, p. 475). Caneca também lembra a familiaridade sua com as ruas por onde passa e com as pessoas as quais vê para logo a seguir calar-se. O povo protesta:

- Por que é que deixou de falar?

Estávamos todos a ouvi-lo.

- Ao passar estava falando, vinha conversando consigo.

- Por que agora caminha mudo se estava falando a princípio?

— Decerto o forçaram a calar-se.

Até os gestos lhe são proibidos.

— Fazem-no calar porque, certo, sua fala traz grande perigo.

- O que lhe ouvi na rua do Crespo

foi "mar azul" e "sol mais limpo".

— Receiam que faça falando desta procissão um comício.

- Dizem que ele é um perigo, mesmo

falando de frutas, passarinhos. (MELO NETO, 1994, p. 476)

Há medo de confusão nas ruas. Um oficial intima Frei Caneca:

— De que fala Reverendíssimo

como se num sermão de missa?

- De toda essa luz do Recife.

Louvava-a nesta despedida.

- Ouvi-o falar em voz alta, como se celebrasse missa.

$\mathrm{Vi}$ que a gente pelas calçadas 
como num sermão, calada ouvia.

- Tanto passeei por essas ruas

que fiz delas minhas amigas.

Agora lavadas de chuva,

vejo-as mais frescas do que eu cria.

— Um condenado não pode falar.

Condenado à morte perde a língua.

- Passarei a falar em silêncio.

Assim está salva a disciplina. (MELO NETO, 1994, p. 477)

Condenado à total mudez, Frei Caneca seguirá falando no espaço do poema. Se a gente nas calçadas não pode mais ouvi-lo, os leitores seguirão com sua voz. Em verso, o condenado despede-se de sua cidade.

- Sob o céu de tanta luz que aqui é de praia ainda, leve, clara, luminosa por vir do Pina e de Olinda, que jogam verde e azul sob o sol de alma marinha, sob o sol inabitável que dirá Sofia um dia, vou revivendo os quintais que dispensam sesta amiga detrás das fachadas magras com sombras gordas e líquidas.

E se não ouço os pregões, vozes das cidades, vivas, revivendo tantas coisas vale qualquer despedida. (MELO NETO, 1994, p. 479)

O cortejo segue pelas ruas do Recife, acompanhado pelo povo que funciona como o coro da tragédia grega que vai comentando os acontecimentos enquanto anuncia o desenrolar da trama. Caneca despede-se da vida e de suas lembranças. A próxima parada é no Adro do Terço onde o Vigário Geral receberá o preso das mãos do Oficial e o execrará conforme determina o Direito Canônico. O Vigário Geral explica a sentença:

- A degradação eclesiástica é uma pena vindicativa, a mais grave de todas as penas eclesiásticas. Ao iniciar-se a degradação, vestem-lhe todos os paramentos sagrados, como se o padre houvesse ainda uma vez de celebrar o sacrifício incruento da redenção. E a cerimônia começa com grande aparato: o celebrante lhe tira das mãos o cálice, a hóstia e a patena. Depois, um a um, o vai despindo dos paramentos sacerdotais. Despem-no finalmente da batina ou hábito religioso. Está o padre degredado das ordens sacras: já não pode exercer o ministério sacerdotal. (MELO NETO, 1994, p. 486)

Após o ritual, Caneca está "nu de toda igreja, em camisa/e calças de ganga grosseira", (MELO NETO, 1994, p. 488). É devolvido à milícia que representa a justiça dos homens. A caminhada do preso é retomada com a gente nas calçadas atenta para sua figura serena:

- Não é jovem, tampouco velho, apesar dos cabelos brancos.

- Veio andando calmo e sem medo, ar aberto de amigo, e brando.

— Não veio desafiando a morte 
nem indiferença ostentando.

- Veio como se num passeio,

mas onde o esperasse um estranho. (MELO NETO, 1994, p. 494)

Logo a seguir aparece a última fala de Caneca no texto, uma própria definição de Cabral a respeito da morte.

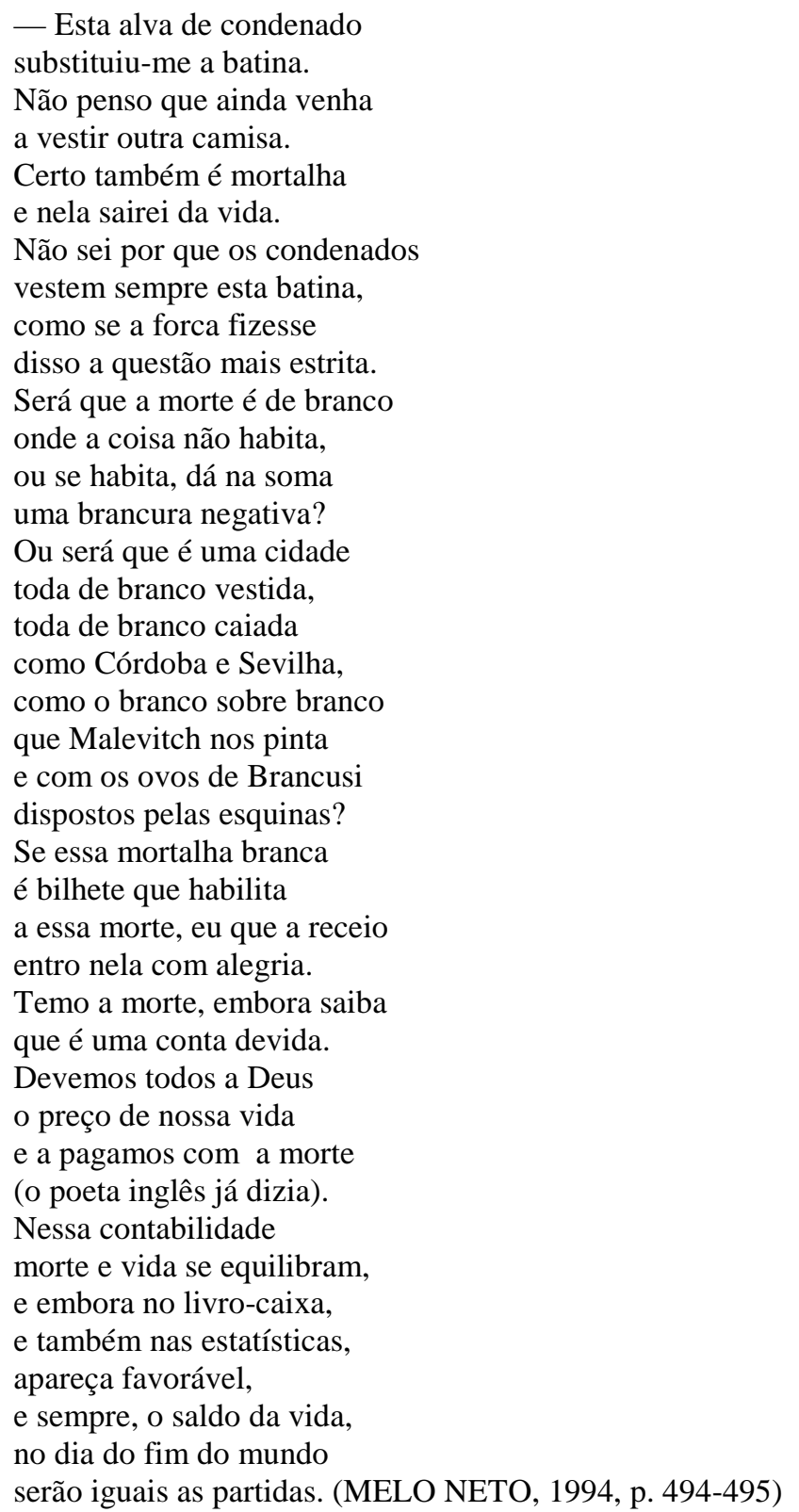

A voz do poeta está alta neste trecho do Auto sobrepondo-se à de Frei Caneca. Córdoba e, principalmente, Sevilha são cidades muito caras a João Cabral. Brancusi é um escultor romeno que viveu entre 1876 e 1957 tem, inclusive, trabalhado com Rodin, em Paris. Fica claro que o poeta quer marcar sua presença no texto e numa parte em que Caneca fala pela última vez. E fala sobre a morte.

Seguindo no caminho mortal, o povo ainda tem esperanças da chegada de um indulto. Enquanto isso, as vozes vão definindo o condenado: 
A GENTE NAS CALÇADAS

- Eu o imaginava homem alto com olhos acessos, de febre.

- Eu o imaginava também um asceta, puro osso e pele.

-É um homem como qualquer um, e profeta não se pretende.

- É um homem e isso não chegou:

Um homem plantado e terrestre. (MELO NETO, 1994, p. 496)

Essa proximidade com o povo justificaria, de certa forma, a torcida para que a sentença não se concretize. $\mathrm{O}$ desejo parece, num primeiro momento, realizar-se: o carrasco nega-se a dar efeito à execução.

- O bom carrasco oficial deve estar aprontando o nó.

— Não quis vir. Diz que matar padre

é morte que recai, veloz.

Fizemos todas as ameaças

e as promessas para depois.

Não quer vir. Diz que matar padre

ou gato, na vida dá nó. (MELO NETO, 1994, p. 497)

Outro carrasco, o Vieira, é procurado, mas se nega. É um homem que irá à forca por assassinato. Outros são procurados na prisão com promessas de liberdade imediata, mas declinam do convite da soldadesca. O impasse está criado, e a gente nas ruas conversa sobre a duplicidade inerente à máquina da morte:

- Uma forca sempre precisa

de um enforcado e de um carrasco.

A forca não vive em monólogos:

dialética, prefere o diálogo.

Se um dos dois personagens falta

não pode fazer seu trabalho.

O peso do morto é o motor, porém o carrasco é o operário. (MELO NETO, 1994, p. 502)

João Cabral parece também estar falando da linguagem neste fragmento, da dialética inerente à palavra, que precisa de alguém que a produza e de alguém que a leia, senão é objeto morto. A palavra seria a forca e carrasco e enforcado, leitores-escritores.

No desespero por um carrasco, nasce a idéia de que seja uma criança vendada a executora da morte. Diz um soldado: "Parece que o melhor carrasco/ é um menino em toda inocência:/ ir buscar no Asilo da Roda /carrasco infantil, mas com venda", (MELO NETO, 1994, p. 503). A venda não tapará os outros sentidos do menino que acabará sabendo do que foi partícipe ou de que teve sua inocência vitimada.

Sem ninguém para executar a pena capital, o destino de Caneca, depois de três horas de espera, será enfrentar os fuzis da tropa de linha:

A GENTE NO LARGO 
- Creio que ao mesmo Frei Caneca essa tropa vem com alívio.

— Leva ali horas esperando, suplício de esperar suplício.

- Para quem está esperando cada minuto vale um espinho.

- E quando a espera é de martírio, vira uma pua cada espinho. (MELO NETO, 1994, p. 505)

\section{A GENTE NO LARGO}

- Esperar é viver num tempo em que o tempo foi suspendido. ${ }^{3}$

- Mesmo sabendo o que se espera, na espera tensa ele é abolido.

- e se quer que chegue ou que não, numa espera o tempo é abolido.

- E o tempo longo mais encurta

o da vida, é como um suicídio. (MELO NETO, 1994, p. 505)

O filósofo alemão Martin Heidegger (1993, p. 26) diz que esperar não é apenas desviar ocasionalmente o olhar do possível para a sua realização, mas, em sua essência, é esperar por ela. Também na espera, dá-se um abandono do possível e um tomar pé do real, pelo qual espera o esperado. É a partir do real e com vistas a ele que o possível é absorvido no real pela espera.

A espera de Caneca, na voz do povo, é pela morte (talvez venha, talvez não, sim). A espera tensa dá a sensação de tempo abolido, tempo suspenso, estancado, longo como um suicídio. Cada minuto é um espinho. O real é a própria morte que se coloca como sentença. Todos vivemos à espera da morte e não sabemos a data certa. A angústia do ‘coro', tomada emprestada de uma possível angústia vivida por Caneca perto de sua hora final, é a do homem que sabe que caminha para morte. E serão doze os atiradores com suas balas de aço a darem fim à espera do Frei. O número é cabalístico:

esse número é de uma grande riqueza na simbologia cristã. A combinação do quatro do mundo espacial e do três do tempo sagrado medindo a criação-recriação, dá o número doze, que é o do mundo acabado. É o da Jerusalém celeste (12 portas, 12 apóstolos, 12 juízes etc.). É o do ciclo litúrgico do ano de doze meses e de sua expressão cósmica que é o zodíaco. (CHEVALIER; GHEERBRANT, 1982, p. 348)

Doze é o número de pessoas escolhidas para executar o fuzilamento. E o fuzilamento cria um problema, pois é dignidade de um militar e não de gente comum a que foi transformado o condenado.

\section{A GENTE NO LARGO}

\footnotetext{
${ }^{3}$ Heidegger, em Ser e tempo (1993, p. 26), diz que é na espera que a presença se comporta frente a algo possível em sua possibilidade: "Para o que está na expectativa, o possível pode vir ao encontro sem obstáculos ou restrições, em seu 'talvez, talvez não ou por fim sim'. [...] Toda espera compreende o 'tem', o seu possível comprometido com o se, o como e o quando ele se realizará enquanto algo simplesmente dado."
} 
- A forca é pena habitual

Para assassinos e bandidos.

- Assim, para mais humilhá-lo

foi condenado a tal suplício.

- Ser fuzilado é a pena digna

do militar, mesmo insubmisso.

— Como ninguém quis enforcá-lo

na hora final foi promovido. (MELO NETO, 1994, p. 510)

Por fim Caneca é morto. Seu pai tanoeiro, depois de rezar todo o dia no asilo onde habita, escuta os tiros ao longe, demorando a entender o significado deles. O corpo é jogado à porta da Basílica do Carmo e a noite prossegue.

Para finalizar vale citar o pensamento de Heidegger: "Findar significa, de início, terminar, e isso num sentido ontológico diverso. A chuva termina. Ela não mais se dá. O caminho termina. Esse findar não faz com que o caminho desapareça," (HEIDEGGER, 1993, p. 26). Caneca morre e a noite prossegue anunciando, implicitamente, a perspectiva do dia.

\section{Referências}

BARBOSA, João Alexandre. João Cabral de Melo Neto. São Paulo: Publifolha, 2001.

. Brasil: nunca mais, um relato para a história. Prefácio de D. Paulo Evaristo Arns. 18 ed. São Paulo: Vozes, 1985.

CHEVALIER, Jean ; GHEERBRANT, Alain. Dicionário de símbolos. 10 ed. São Paulo: Rio de Janeiro. José Olympio, 1982.

HEIDEGGER, Martin. Ser e tempo: parte II. 3 ed. São Paulo: Vozes, 1993.

MELO NETO, João Cabral de. Obra completa. Rio de Janeiro: Editora Nova Aguilar, 1995.

SODRÉ, Nelson Werneck. História da Imprensa no Brasil. São Paulo: Martins Fontes, 1983. 